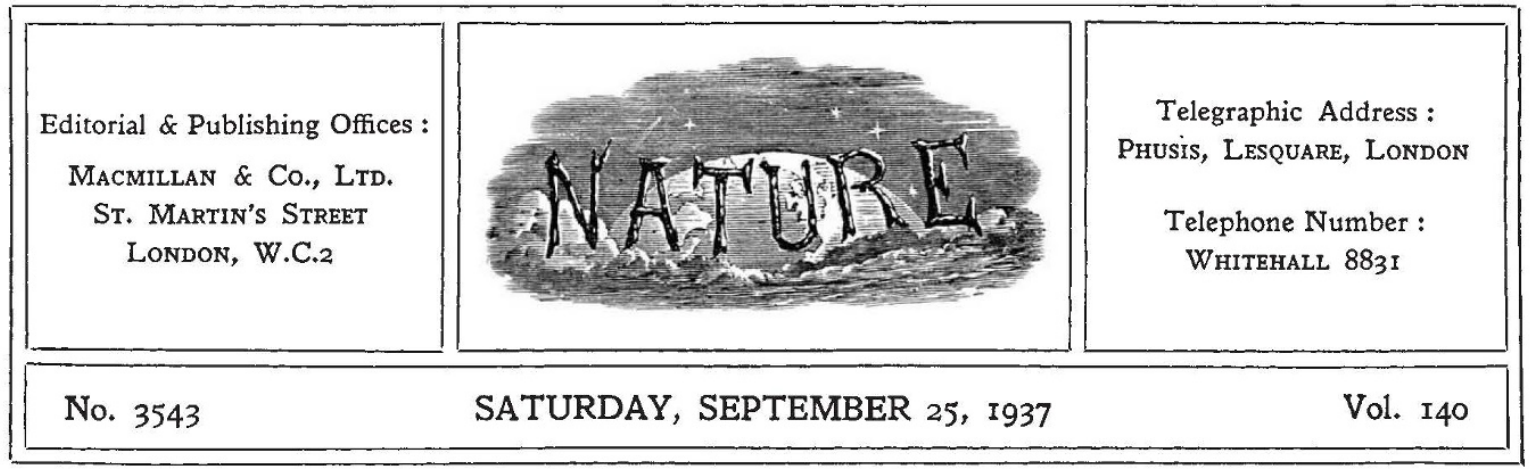

\title{
The Organization of Social Research
}

$\mathrm{E}$ VERY year the social services of Great Britain tend to attract increased attention and generally to demand increased expenditure of public money. This may be all to the good; but from time to time it is desirable to attempt to survey the situation and to consider whether in practice these services are being adequately directed by controlled and informed social research. In a field of this kind, where the boundaries are extremely wide and the claims in every direction are most insistent, constant and wise research is particularly necessary if undue waste is to be avoided and if merely sectional interests are to be held in reasonable control.

As things are at present, our problems of public health have been placed upon a sound foundation, mainly through the organization and activities of the Ministry of Health and later of the Medical Research Council. Research in agriculture is now being similarly promoted by the more recently established Agricultural Research Council. The National Physical Laboratory and the Department of Scientific and Industrial Research, likewise subsidized by the State, have brilliantly developed the contributions which can be made by physics and chemistry to a great variety of industrial and even social problems. The Industrial Health Research Board, with far more slender resources and with a less independent status, has made valuable contributions to some of the problems of industrial life. So far as national organization goes, that is all. Other problemseconomic, educational, biological, psychological, sociological - are left to advisory or to consultative committees, which can receive 'evidence' and issue reports (but do little else), or to private enterprise and sporadic effort.
It is high time to alter this state of affairs-to establish a new scientific body, with adequate endowment from the State, which will do for human social research what the Medical Research Council does for public health, what the Agricultural Research Council is beginning to do for agriculture, and what the Department of Scientific and Industrial Research does for the applications of physics and chemistry. Such a body must be nationally constituted; for most of the problems which it would be asked to study are the immediate and practical concern of existing government departments.

Everywhere, and in all directions, the most prodigious efforts are now being made to bring differently organized social groups into peaceful and lasting co-operation. But we have much yet to learn about the nature and extent of these differences; for example, of class-differences and of class-conflicts. In industry, in education, in politics national and international, in science, and in religion, it is essential that bases of successful co-operation be found-or the world as we know it must disappear in faction, enmity and confusion.

Scientific invention and popular education have combined to bring groups widely different in language, or tradition, or custom, or aim, or all of these, into close contact; and every day potentialities of conflict threaten to become actual or even to break into sharp strife producing lasting irritation and lamentable waste. Many of the best minds are set to devise all manner of elaborate machinery for promoting and preserving friendly relations between groups. Yet if but a fraction of the intelligence that has been put to work upon this problem of machinery had been devoted to a study of those human conditions 
which will inevitably wreck even the most wisely devised machinery, there would have been great economy and far more to show for the effort. The methods for a controlled study of the bases of group co-operation-and of consequent government by consent-are to hand. They can be made as scientific and as definite as those of the investigation of any other human problem. They require wide application, for which centrally and nationally organized effort is necessary.

It is clear that at the present day the great mass of the work of the world can be performed efficiently with a relatively slender equipment of intelligence, and-what is probably more important still-with only a small basis of acquired knowledge. This is due to the enormous advances of physical science and especially to the modern applications of engineering. The great requirement now, so far as the working-day activity of the masses goes, is for specialized skills, not for extensive knowledge. Moreover, the time during which these specialized skills must be kept continuously in operation in order that the basic needs of civilization may be satisfied is all the while decreasing. We may even say, with an approximation to truth, that, apart from the institutions devoted to technical training, modern popular education is now designed mainly for leisure, not for work.

We know, however, extraordinarily little of how, if at all, the majority of workers in any section of a modern community utilize their education for their leisure, and even less about how and how wisely leisure occupations are chosen and how they affect social and workaday behaviour. There can be no doubt that the views, opinions and beliefs which influence public policy in many directions are stimulated and developed chiefly during periods of leisure. Consequently, the most stable community in modern social life appears likely to be the one in which leisure is ample and most ably employed; and as science still further advances its techniques, the truth of this will become even more obvious. It is not, therefore, surprising that serious attention is at length being given to stimulating the study of leisure and of its influence in human affairs; but this study needs adequate control and organization.

Bound up with the increasing importance of leisure is the fact that leisure has itself become possible largely as a result of a great speeding-up in the tempo of work and in the specialization of routine processes. There is a general impression that these two conditions-speeding-up and increase of routine--are exerting profound influences upon human behaviour and consequently upon social policy. They may be responsible for special occupational difficulties or disorders, the study of which overlaps the field of medical research. They may give rise to a degree of dissatisfaction which inevitably results in various forms of group conflict. They may encourage individual maladjustments to an extent which has wide repercussions upon family and social life. Whether or no they do these things, in what directions, how and when, are all matters for speculation at the present time; but they could be made matters of far more certain knowledge.

The general drift of social development for many years past seems to have been for more and more of the functions which were formerly those of small groups to become the direct practical concern of larger ones. Thus the functions of the familyso often in a vague way said to be disastrously breaking down—in regard to education, health, industrial training, and many everyday regulations of behaviour, have passed largely to some wider authority constituted within the nation group. Similarly, the functions of local religious, industrial and general administrative groups have in many instances been lost or become strictly controlled. Coincidently, human loyalties, partly by training and propaganda, partly by natural drift, seem to have been diverted from the smaller to the larger groups, or to have changed in character as regards the smaller groups. On one hand, any more forcible and competent social group must be able to perform functions on behalf of its members better than any smaller, less organized group can do ; and on the other hand, every large modern society, such as the nation group, must necessarily contain and maintain in very great variety internal social differentiation. A study, therefore, by experimental and observational methods, of the place and functions of small groups in a large society, would have a close bearing upon many urgent problems of practical social control.

These are a few only of a large number of other general problems (for example, those of population and of crime) upon the solution of which the effectiveness and stability of present and future social organization depend. They are matters of daily debate and speculation; and in that stage they will remain, unless they are conceived, as they properly should be, as problems in higher human biology, to be attacked, not by dialectic 
alone, but by experiment when possible and by controlled observation. Methods for such an attack are already being devised and applied. But they will have little chance of success, unless they can attract the attention of, and be refined and sharpened by, the best scientifically trained minds available.

Besides these general problems, there is a mass of more specialized questions which call for immediate and organized research. Much brilliant recent physiological investigation, on 'conditioning', on habituation, on adaptation, on inhibition and on the development of co-ordinated motor activity, has its most significant application to human behaviour. The last ten years have seen the study of the operation of incentives and 'drives' placed upon a much firmer basis in so far as the behaviour of animals is concerned; but virtually nothing is known, except in a speculative sense, about their conditions and mode of operation in human society. Modern civilization depends to a considerable extent upon skills of one kind and another, yet we are only at the outset of ascertaining the principles which determine how different skills can best be acquired and maintained. In region after region, throughout the British Empire, wherever native populations are being rapidly caught up in modern Western ways of life, urgent practical difficulties concerning education, administration, and the swift transformation of manners and customs arise and cannot be postponed. As things are, the administrator is forced to do his best to meet such problems ad hoc and in a hurry. There are principles underlying the correct solution of them all; but these principles demand organized research for their discovery, and hitherto the State has given no systematic support for such research.

Indeed, at the present time in Great Britain, if a government department, or any outside person or body, is brought up against some research problem underlying the administration of any branch of the social services, there is little that can be done beyond referring it to the Medical Research Council or to an advisory committee. This is scarcely fair. The Medical Research Council is usually sympathetic ; but many of the problems thus proferred are remote from its terms of reference, and in any event its resources are insufficient to do much more than meet its own immediate concern with public health in the specifically medical sense of the phrase. Also, though an advisory committee can inquire into whatever research may be in progress and can collect opinions, it cannot initiate original investigations on an adequate scale.

A new, centrally constituted scientific body is urgently needed, to survey the field of social research and to set on foot considered programmes of actual investigation on higher biological lines. The questions demanding study are most of them border-line problems, at the growing points of research in different departments of science, involving organized and many-sided efforts for their solution. There is no government department that could not profit vastly from such an enterprise. Ultimately the public purse would be saved from much wasteful expenditure, and the country's social services set upon a firmer foundation of well-attested knowledge.

\section{Exploration in Iran}

Archæological Reconnaissances in NorthWestern India and South-Eastern Irān Carried out and recorded with the support of Harvard University and the British Museum by Sir Aurel Stein. Antiques examined and described with the assistance of Fred H. Andrews and analysed in an Appendix by R. L. Hobson. Pp. $\mathrm{xx}+267+60$ plates. (London: Macmillan and Co., Ltd., 1937.) 63s. net.

$\mathrm{A}^{\mathrm{H}}$ FTER forty years of research and exploration in and around Central Asia, Sir Aurel Stein found himself constrained by the intolerable character of the conditions imposed on his activities by the Chinese Government to cease from further investigation in a field which he had regarded as the major objective of his studies. While he has every sympathy in his personal disappointment and frustration when the expedition in Inner Mongolia was abandoned, the loss to science by the diversion of his experience and knowledge to other regions is felt to be a calamity. Nevertheless, there is compensation of a kind in the fact that by an arrangement with Harvard University and the British Museum, which were his sponsors, he was able to turn to the exploration of regions of the Middle East, which were still archæologically unexplored and geographically imperfectly known. 